\title{
BRASILIANA E RECONQUISTA Do BRASIL: PROJETOS EDITORIAIS DE TRADUÇÕES
}

\author{
Brasiliana and Reconquista do Brasil: \\ editorial translation projects
}

\author{
Cristina Carneiro Rodrigues*
}

\begin{abstract}
RESUMO
O objetivo deste trabalho, de cunho historiográfico, é comparar projetos editoriais de traduções de narrativas sobre $o$ Brasil escritas por viajantes estrangeiros publicadas em duas coleções: a Brasiliana, da Companhia Editora Nacional (anos 1940), e a Reconquista do Brasil, da Itatiaia em conjunto com a EDUSP (anos 1970). Ambas têm propósitos similares, publicar obras que descrevam o Brasil e os brasileiros, mas, enquanto a primeira oferece eminentemente textos escritos por autores nacionais, a segunda abre maior espaço para traduções. A diferença mais evidente entre as coleções é que, enquanto a Brasiliana concede espaço para os tradutores exporem, em seus prefácios e notas, suas posições sobre o autor, a obra, assim como seus projetos tradutórios, a Reconquista do Brasil publica poucas notas e prefácios dos tradutores. As comparações entre as edições exploram a diferença entre os enfoques dados às obras pelas diferentes orientações institucionais.

Palavras-chave: coleção Brasiliana; coleção Reconquista do Brasil; história da tradução no Brasil.
\end{abstract}

\footnotetext{
ABSTRACT

The purpose of this historiographical work is to make a comparison between editorial translation projects of narratives about

${ }^{*}$ UNESP - São José do Rio Preto.
} 


\begin{abstract}
Brazil written by foreign travelers published in two collections: Brasiliana, by Companhia Editora Nacional (1940s), and Reconquista do Brasil, by Itatiaia jointly with EDUSP (1970s). Both have similar goals, that is, to publish works describing Brazil and Brazilians, but, whereas, the former mostly offers texts written by domestic authors, the latter makes greater room for translations. The most apparent difference among the collections is that, while Brasiliana makes allowances for translators to reveal, in their prefaces and notes, their views on the author, the work, as well as their translation projects, Reconquista publishes few notes and prefaces by translators. The comparisons between the editions explore the difference between the focus given to the works by different institutional guidelines.
\end{abstract}

Keywords: Brasiliana Collection; Reconquista do Brasil Collection; translation history in Brazil.

Os anos 1930 a 1950 constituem-se, de acordo com Pagano (2001), como a época do boom editorial brasileiro, que tanto foi um boom da tradução, quanto da publicação de coleções. Além de coleções para diferentes segmentos de público, as grandes editoras do período, exceto a Globo, em consonância com o anseio de se conhecer melhor o Brasil, lançaram coleções de livros sobre o Brasil. Procurava-se tomar "uma atitude crítica em face do que se chamava incansavelmente a 'realidade brasileira' (um dos conceitos-chave do momento)", busca que "se encarnou nos 'estudos brasileiros' de história, política, sociologia, antropologia, que tiveram incremento notável, refletido nas coleções dedicadas a eles" (CANDIDO, 1987, p. 190).

Com o objetivo de "desvendar, mapear, estudar e diagnosticar a realidade brasileira" (PONTES, 1989, p. 359), em sintonia com o quadro de interesse pelo Brasil gerado pelo governo, que envolveria a criação de um movimento de unificação cultural e a noção de "civilizar" o país, conceberam-se as três mais importantes coleções de assuntos brasileiros editadas na era Vargas: a Brasiliana, criada em 1931 pela Companhia Editora Nacional (série da Biblioteca Pedagógica Brasileira); a Documentos Brasileiros, lançada em 1936 pela Editora José Olympio; e a Biblioteca Histórica Brasileira, produzida a partir de 1940 pela Livraria Martins Editora. Grande parte dos volumes dessa última foram reeditados nos anos 1970 pela editora Itatiaia em parceria com a EDUSP, na coleção Reconquista do Brasil.

Não há traduções publicadas na Documentos Brasileiros. Nas outras há, especialmente de relatos de viajantes e naturalistas. Considerando que a Brasiliana foi inaugurada cerca de 40 anos antes da Reconquista do Brasil, e que há títulos em comum entre elas, com traduções feitas por 
diferentes tradutores, o objetivo deste artigo, de cunho historiográfico, é comparar os projetos editoriais das duas coleções, enfocando o tratamento dispensado às obras traduzidas nas duas diferentes épocas. Em um primeiro momento, descreverei as coleções, depois apresentarei cinco pares de projetos editoriais de traduções para, em um terceiro momento, apontar sua sistematicidade ou falta dela.

A coleção Brasiliana, da Companhia Editora Nacional dirigida por Octalles Marcondes Ferreira, faz parte de uma das mais importantes coleções do cenário nacional na primeira metade do século XX: a "Biblioteca Pedagógica Brasileira", projetada pelo intelectual e educador Fernando de Azevedo. Na análise de Candido (1987, p. 192), a Coleção Brasiliana "foi um marco decisivo, não apenas pela reedição de clássicos estrangeiros e nacionais, mas pelo estímulo aos contemporâneos". Seu objetivo era divulgar a cultura e o pensamento brasileiro, assim como o conhecimento científico sobre o Brasil. Isso significava publicar eminentemente produção nacional, mas envolvia também editar traduções de obras estrangeiras sobre assuntos brasileiros. A coleção é composta de cerca de 400 volumes, apenas por volta de $15 \%$ deles traduzidos, a maior parte relatos de viajantes e naturalistas, especialmente os que estiveram no Brasil no século XIX. Esteticamente, é muito modesta: os livros são pequenos, com $13 \mathrm{~cm}$ de largura por 18,5 de altura, com capas de papelão, impressas em duas ou, no máximo, três cores. Muitas das traduções trazem o nome do tradutor na capa. Nos casos em que não está na capa, está na página de rosto, com referência à sua titulação ou à academia de que é membro. Quando não é o tradutor quem assina o prefácio ou as notas, o nome do autor desses paratextos consta na capa ou na página de rosto.

Em 1973 inaugura-se a coleção Reconquista do Brasil, resultado de uma parceria entre a Editora Itatiaia de Belo Horizonte e a Editora da Universidade de São Paulo. Seu primeiro volume traduzido é de 1975 e o quarto da série: Viagem pelas províncias do Rio de Janeiro e Minas Gerais, do naturalista Auguste de Saint-Hilaire. ${ }^{1}$ Hallewell (2005) caracteriza essa coleção como uma imitação da Coleção Brasiliana. Se pensarmos pelo ângulo de que reúne material sobre o Brasil, realmente se assemelha a ela. Mas, como vou argumentar neste trabalho, há diferenças significativas que começam pelos títulos escolhidos para as coleções. Enquanto "Brasiliana" indica uma coleção de obras sobre o Brasil, "reconquista" remete a recuperar, a tornar a obter algo que se havia perdido. Se lembrarmos que a situação política no início dos anos 1970 estava difícil, e que em 1975 a morte de Vladimir Herzog desencadeou todo um movimento de vários setores da sociedade pela rede-

Os volumes 1 e 2 são atualizações de textos de estrangeiros feitas pelo diretor da coleção, Mário Guimarães Ferri, e o volume 3 é de sua autoria. 
mocratização do Brasil, talvez o que se deseje reconquistar seja a democracia. Mas "conquistar" não se refere apenas a ocupar um espaço, relaciona-se também a cativar, atrair o amor de alguém. Nesse sentido, "reconquista" se associaria a conhecer o Brasil, reconhecê-lo, para gostar mais dele. Gisella de Amorim Serrano (2010) afirma que o título "sinaliza para a invocação de uma espécie de 'retomada histórica' porque reconquistar é também refazer, restaurar" (SERRANO, 2010, p. 2). Essa autora entende que as publicações dessa coleção teriam a finalidade de "recuperar ou reinterpretar aspectos históricos brasileiros, atribuindo-lhes novos significados construídos a partir de propósitos determinados por um programa editorial pré-definido" (SERRANO, 2010 , p. 5) que se relaciona com a seleção dos títulos publicados. Serrano (2010) não comenta a questão da apresentação dos livros e das traduções, que eu acho relevantes para entender o projeto da coleção.

A coleção Reconquista do Brasil tem, no total, 306 volumes, divididos em 3 séries. A primeira apresenta 60 títulos, 80\% traduções de relatos de viajantes, começando por Hans Staden, mas não publicados em ordem cronológica. A segunda série tem 233 volumes; até o volume 100, cerca de $50 \%$ são traduções, muitas delas republicações da Biblioteca Histórica Brasileira da Martins. A terceira série é dedicada a livros de arte e tem apenas 13 volumes. A proporção de traduções dessa coleção é, portanto, muito maior que a da Coleção Brasiliana, o que já diferencia os projetos editoriais. Além disso, a Brasiliana publica traduções feitas especialmente para a coleção, ou publicadas anteriormente por editoras regionais, com edições esgotadas, e a Reconquista do Brasil publica eminentemente traduções feitas para a Biblioteca Histórica Brasileira, da Martins.

O que Genette (2009) chama de peritexto editorial, ou seja, a realização material do livro, também é muito diferente, pois nos anos 1970 os livros já são considerados como produtos de consumo, têm uma circulação maior e precisam ser atraentes. E, nesse aspecto, os livros da Coleção Reconquista do Brasil são extremamente bem cuidados.

Os livros da primeira série são grandes, com $18 \mathrm{~cm}$ de largura por 27 de altura; os da segunda série são menores, com $16 \mathrm{~cm}$ de largura por $22 \mathrm{~cm}$ de altura. As capas são impressas a quatro cores, cada uma com uma ilustração diferente assinada pelo artista plástico Cláudio Martins. O papel é encorpado, com $85 \mathrm{~g} / \mathrm{m}^{2}$ de gramatura e, de acordo com a informação prestada no final dos volumes, fabricado especialmente para a coleção. Os exemplares têm orelhas, com uma apreciação do livro; no caso das traduções dos relatos de viajantes os textos geralmente assinalam seu valor de documento histórico. Mário Guimarães Ferri, presidente da comissão editorial da EDUSP até 1985 e diretor da coleção, assina grande parte das apresentações, abordando a biografia do autor ou as circunstâncias da escritura do livro. 
Não tenho dados que me permitam afirmar categoricamente que ele escolheu os títulos a serem publicados, mas normalmente é o editor que seleciona os livros que compõem uma coleção. Como Ferri (1979-1980) escreveu uma história da botânica no Brasil salientando o papel dos viajantes-naturalistas para o desenvolvimento da área no país e mencionou explicitamente as traduções publicadas pela Coleção Brasiliana e pela Biblioteca Histórica Brasileira, a decisão de publicá-los pode perfeitamente ser sua.

Nos volumes traduzidos da coleção Reconquista do Brasil são tomados alguns cuidados que não eram frequentes na década de 1970, nem o são hoje. O nome do tradutor geralmente está na página de rosto e normalmente a edição em que se baseou a tradução é informada no verso da página de rosto ou por Ferri, na Apresentação do livro ou em seu Prefácio. Esses paratextos do diretor da coleção trazem com frequência apreciações sobre as traduções. Em Um naturalista no Rio Amazonas, de Bates, ele informa que a tradutora "Dona Regina Regis Junqueira é muito cuidadosa" e ele apenas teria introduzido "algumas modificações de ordem técnica e poucas notas de rodapé" (BATES, 1979, p. 11). Na tradução de Viagem ao Brasil, relato do casal Agassiz, ele inclui uma biografia e uma bibliografia do tradutor, acrescentando que teve "apenas que fazer alterações em assuntos de natureza científica" e incluir algumas notas trazendo "esclarecimentos e informações visando a atualizar conhecimento que, com o decurso do tempo, especialmente em assuntos de ordem taxonômica, sofrem modificações" (AGASSIZ; AGASSIZ, 1975, p. 7). Em Viagem ao interior do Brasil, de Gardner (1975), faz observações similares, além de informar que o tradutor faleceu e quais os livros que traduziu.

Nesse aspecto a Reconquista do Brasil também difere da coleção Brasiliana. O diretor da Brasiliana não se pronuncia. ${ }^{2}$ São os tradutores ou especialistas na área que se encarregam das apresentações, prefácios e notas. Não há indicação de que o editor da série tenha lido as traduções, nem que tenha escolhido os títulos, os textos de partida ou definido estratégias tradutórias. Pelo contrário, os tradutores parecem ter muita liberdade para definir como proceder (cf. RODRIGUES, 2008). Os prefácios escritos pelos tradutores informam que eles é que decidiam se iriam ou não atualizar os conhecimentos, fazer esclarecimentos ou trazer novas informações sobre $o$ assunto em pauta. E, dependendo do projeto por eles seguidos, há tradutores que o fazem, há os que não o fazem. Há os que fazem correções no corpo do texto, os que as fazem em notas de rodapé, os que apenas indicam que há um equívoco do autor. 
Ferri, por outro lado, parece ter lido todas as traduções, porque em muitas delas há notas em que não só faz comentários sobre a informação dada pelo autor, como faz observações sobre a tradução. Por exemplo, na tradução do relato do viajante britânico Richard Francis Burton, em um momento em que o autor diz que no Brasil come-se muita carne de porco, como no Oeste dos Estados Unidos e na China, "onde o povo é quase que feito de carne de porco", ele assinala, em nota: "essa forma bizarra de descrever uma situação real é do próprio original. (M. G . F.)” (BURTON, 1976, p. 101). ${ }^{3}$

Localizei, nas bibliotecas das universidades estaduais paulistas, doze obras publicadas nas duas coleções, três traduzidas pelo mesmo tradutor, e nove com traduções assinadas por tradutores diferentes. Isso significa que a Reconquista do Brasil, além de reeditar as obras da Biblioteca Histórica Brasileira, republicou traduções feitas para outras editoras e também produziu algumas. Neste trabalho vou abordar os projetos editoriais de cinco, das nove traduções feitas por diferentes tradutores, buscando salientar suas diferenças, assim como a regularidade, ou a falta de, dos projetos.

o primeiro par de traduções examinadas foi a publicação da narrativa do ex-cônsul britânico em São Paulo, Sir Richard Francis Burton. Seu relato da viagem pelo Brasil foi publicado, em Londres, em 1869, em dois volumes, como Explorations of the highlands of the Brazil with a full account of the gold and diamond mines. A coleção Brasiliana subdividiu a obra em três volumes, o primeiro publicado em 1941, intitulado Viagens aos planaltos do Brasil (1968), como número 197, tendo recebido o subtítulo "Do Rio de Janeiro a Morro Velho". A tradução é do historiador Américo Jacobina Lacombe, cujo nome está na capa. Nessa primeira edição, há apenas uma curta nota preliminar do tradutor de três parágrafos para explicar a sistematização que fez das muitas notas de rodapé que insere, e agradecer aos revisores. Em 1983 esse primeiro volume recebe uma segunda edição, com um prefácio e orelhas assinadas pelo tradutor, e é apenas nessa época que são publicados o segundo e o terceiro volumes. ${ }^{4}$ Muitas das notas de

${ }^{3} \mathrm{O}$ trecho do original a que Ferri se refere é: This adipose tissue of boned, disembowelled and unfleshed pig, slightly salted, is hygienically well adapted to beans, combining carbon with nitrogen; unfortunately it enters into almost every dish, and it does no good to the digestion of "Young Brazil". The same may be said of many places in the Western United States and China, where people are almost made of pork. Apparently it is a favourite food in young lands. In Europe we are told during many centuries the only animal food generally used was pork. (BURTON, 1869, p. 104)

${ }^{4}$ O segundo volume recebeu o número 375 na coleção e o subtítulo "Minas e os mineiros"; o terceiro é o número 376, "O rio São Francisco". Ambos foram publicados em 1983 e consta, na ficha catalográfica, tratar-se de segunda edição, mas os números na coleção evidenciam que foi sua primeira publicação. Para corroborar essa informação, busquei em várias bibliotecas as primeiras edições desses volumes, sem encontrá-los. Além disso, verifiquei que o volume número 377 da Brasiliana, de 1983, é uma terceira edição, mas as anteriores, de 1960 e de 1952, são de outras editoras. O volume 378, de 1984, é uma primeira edição. Não tratarei aqui das segundas edições da Coleção Brasiliana, porque recebem novos projetos editoriais e incluem outros elementos paratextuais. 
Lacombe são dedicadas a explicar ao leitor que determinada expressão foi escrita em português no original, mas não consta a informação de que Burton traduz poemas e canções brasileiros para seus leitores ingleses (cf. RODRIGUES, 2010).

O título publicado pela Brasiliana inclui ainda a dedicatória de Burton a Lord Stanley, o prefácio de sua esposa e o Canto VI de Os Lusíadas, de Camões, sem qualquer indicação de que estava traduzido no texto de partida. Esse mesmo material é incorporado nos volumes da coleção Reconquista do Brasil, acrescido da Apresentação de Ferri, intitulada "Quem é Richard F. Burton" e de uma "Nota da editora", sem assinatura, em que se justificam os títulos atribuídos aos dois volumes, Viagem do Rio de Janeiro a Morro Velho (1976) e Viagem de Canoa de Sabará ao Oceano Atlântico (1977): remeteriam ao itinerário do viajante, não a planaltos, como no título da Brasiliana e de Burton [highlands]. A tradução é de David Jardim Junior, as orelhas salientando o valor de documento da obra são de Vivaldi Moreira, e as poucas notas são de Ferri.

O segundo projeto editorial de duas diferentes traduções que examino é o do relato da viagem de Henry Bates pela Amazônia. O naturalista no Rio Amazonas em tradução do biólogo paraibano Candido de Mello-Leitão foi publicada em 1944 na coleção Brasiliana, em dois volumes e é baseada na primeira edição em inglês. Além de trazer os prefácios de Bates à primeira e à segunda edições e uma resenha do livro assinada por Charles Darwin, inclui um prefácio do tradutor, em que discorre sobre o autor, suas pesquisas e traz informações sobre seu projeto tradutório. Mello-Leitão assina mais de quinhentas notas de rodapé, de cunho histórico e biológico.

A publicação da Coleção Reconquista do Brasil, Um naturalista no Rio Amazonas, foi baseada na segunda edição britânica da narrativa de Bates, que o próprio autor condensou em apenas um volume. As orelhas são assinadas por João Etienne Filho, a apresentação e as notas explicativas ou retificadoras por Mário Guimarães Ferri, e a tradutora, Regina Regis Junqueira, apenas acrescenta uma nota, para informar que o trecho estava em português no original. ${ }^{5}$ Enquanto a tradução de Regina Regis Junqueira é correta, o texto de Mello-Leitão é muito elegante e tende ao uso de termos mais específicos da biologia, assim como de regionalismos.

No relato de viagem de Alfred Russel Wallace, companheiro de Bates por um período na Amazônia, não se pode falar de diferenças a respeito da coletânea de material apresentado. o que as distingue, nesse sentido, é que o exemplar da Coleção Brasiliana traz of fac-símile da página de rosto da primeira edição do livro em inglês. Nessa edição não é o tradutor, Orlando

\footnotetext{
${ }^{5}$ Além do trecho que ela assinala, há inúmeros outros em português, não destacados.
} 
Torres, que assina as notas, é o prefaciador, o historiador Basílio de Magalhães. Nesse caso, entretanto, a escolha de um historiador para escrever as notas foi questionada pelo naturalista Candido de Mello-Leitão, que traduziu e anotou Bates, com a seguinte afirmação: "é de lamentar que a tradução do livro de Wallace tenha sido inçada de erros nas notas referentes à História Natural" (BATES, 1944, p. 156).

Mas a tradução do texto de Wallace da coleção Reconquista do Brasil apresenta um diferencial em relação às anteriores: não há notas de Ferri, mas há notas do tradutor Eugênio Amado. ${ }^{6}$ Há, ao final de cada capítulo, várias notas, algumas assinaladas como "N. do T.", grande parte remetendo à grafia de palavras do original. Por exemplo, no texto consta que Wallace gostaria de ver "o pavão" (WALLACE, 1979, p. 39), e a nota explica: "o autor refere-se ao pavãozinho-do-pará, no original pavon (N. do T.)” (p. 43). Na apresentação, Ferri informa que há outra edição do livro em português, feita em 1939, mas ela seria pouco conhecida. Ainda que ele não indique, trata-se da edição da coleção Brasiliana, a única localizada com essa data de publicação.

o quarto par de projetos que analisei foi o do relato de viagem de George Gardner. Diferentemente das outras traduções da Coleção Brasiliana analisadas, esta não tem apresentação ou prefácio, nem de um especialista nem do tradutor Albertino Pinheiro. Esse toma a palavra uma única vez por todo o livro de 467 páginas, no ponto em que Gardner fala sobre "arbustos enfezados, a que os habitantes de Minas Gerais dão o nome de carrascais", para informar, em nota, que "o autor usa uniformemente a fórma carrasco. N. do T." (GARDNER, 1942, p. 359). Além disso, com total falta de elegância, o tradutor acrescenta "(sic)" a termos do autor, indicando que ele está equivocado. $O$ procedimento desmerece o texto do naturalista e torna difícil sua leitura. As inserções interrompem o fluxo de leitura e, para os que não sabem que "sic" indica que o termo ou expressão é reprodução exata do texto de partida, por errado ou estranho que possa parecer, não fazem sentido. Por exemplo, lemos, como em outros trechos, "visgeira (sic)" (p. 157), "guava (sic)" e "Arrudo (sic)" (GARDNER, 1942, p. 158). Essas palavras são todas normalizadas no texto da coleção Reconquista do Brasil, traduzido por Milton Amado: visgueira, goiaba e arruda (GARDNER, 1975, p. 96). Milton Amado (1913-1974), pai de Eugênio Amado e coautor da primeira tradução de Quixote no Brasil, explica, na orelha, que se trata de uma reedição da obra. Ferri, em sua apresentação comenta que a tradução é de excelente qualidade, feita pelo "recentemente roubado ao nosso convívio" Milton Amado (GARDNER,

${ }^{6}$ Em 1983, Eugênio Amado (1942- ), filho do tradutor Milton Amado, publicou sua tradução do Quixote pela Editora Itatiaia, sendo esta a segunda tradução brasileira da obra cervantina. 
1975, p. 10), de quem comenta outras traduções. Ferri também informa que essa tradução é uma reedição, mas não remete à edição anterior e eu não encontrei o livro, mas certamente não é da Biblioteca Histórica Brasileira. No volume da Coleção Reconquista do Brasil não há notas do tradutor, apenas do autor e de Ferri, para esclarecimentos, complementações, ou correções. Por exemplo, quando Gardner se queixa do "inseto a que os brasileiros chamam carrapato", Ferri explica, em nota, não se tratar de inseto, "mas de animais da classe Arachnida", que "possuem oito pernas, enquanto os insetos possuem apenas seis (M. G. F.)” (GARDNER, 1975, p. 139).

Por fim, examinei as traduções do relato do casal Luiz e Elizabeth Agassiz atribuídas a dois diferentes tradutores. O livro, na coleção Brasiliana, foi traduzido a partir da tradução francesa por Edgar Süssekind de Mendonça, que traduziu mais três volumes para a coleção, um em parceria com Elias Dolianiti. O tradutor, que tem seu nome na capa do livro, assina as notas explicativas ou retificadoras, mas são mantidas as notas do tradutor francês. Na Coleção Reconquista do Brasil consta que a tradução foi feita, a partir da tradução francesa, por João Etienne Filho, que assina a orelha de vários volumes e tem outras traduções publicadas na coleção. Todas as notas do volume são de Luiz Agassiz, de Ferri, para as atualizações e correções, ou do tradutor francês. Na Apresentação do livro, Ferri informa o nome do tradutor e, após 21 linhas de sua biografia, afirma: "com tal currículo, não é de admirar que a tradução feita por João Etienne Arreguy Filho, do livro de Agassiz, seja de excepcional qualidade" (AGASSIZ; AGASSIZ, 1975, p. 7). Ele teria apenas feito algumas "alterações em assuntos de natureza científica" e acrescentado notas visando a atualizar conhecimento, "especialmente em assuntos de ordem taxonômica" (AGASSIZ; AGASSIZ, 1975, p. 7).

Apesar desses elogios, na última página do livro, após o índice onomástico e toponímico, e antes da última capa, há o seguinte texto, inserido em uma moldura simples:

Em virtude da complexidade de tradução ou de atualização da presente obra, por mais cuidadosa que tenha sido a revisão, vários enganos passaram despercebidos. Uma eventual futura edição corrigirá tais falhas. Agradeceríamos sugestões para essa correção (AGASSIZ; AGASSIZ, 1975, não paginado).

Não há menção à autoria desse texto, que indica que a tradução não é tão boa quanto descreve Ferri na Apresentação e sugere que seja uma "atualização" de publicação anterior. Efetivamente, observei que a tradução de João Etienne Filho é muito próxima à de Edgar Süssekind de Mendonça. Títulos e subtítulos dos capítulos são quase iguais, mas por todo o texto 
similaridades são encontradas. Por exemplo, temos no volume da coleção Brasiliana a seguinte descrição de um peixe: "exemplar de boca alongada, da família dos Goniodontes, que parecia à primeira vista com o nosso Syngnatus comum, mas que realmente se aproxima muito de Acestra" (AGASSIZ; AGASSIZ, 1938, p. 292). Na obra da Coleção Reconquista do Brasil o texto difere quanto às indicações taxonômicas: "exemplar de boca alongada, da família dos Syngnathildae, que se parecia à primeira vista com o nosso Syngnathus comum, mas que realmente se aproxima muito de Acestra" (AGASSIZ; AGASSIZ, 1975, p. 148).

As características dessas traduções que descrevi evidenciam que a coleção Brasiliana não tem um projeto editorial delineado para todos os poucos volumes traduzidos, ou seja, não há sistematicidade no projeto editorial das traduções. Além das capas e da ausência da voz do editor nos volumes, nada mais é constante, pois ora há inserção de muito material paratextual, ora não. Esse dado, entretanto, transforma-se em um ponto positivo, da perspectiva dos tradutores, pois eles recebem espaço para elogiarem ou criticarem os autores e obras e, em seus prefácios ou notas, exporem suas concepções de tradução. Nos projetos aqui analisados, apenas dois tradutores, Orlando Torres e Albertino Pinheiro não o fazem. Aos demais, dá-se a visibilidade e a liberdade que os tradutores almejam. Assim, a regularidade da coleção Brasiliana não se dá no projeto de apresentação das traduções - o "tema Brasil" é que é "central no programa da Brasiliana, explicitando permanentemente a identidade da série" (TOLEDO, 2010, p. 150).

Esse tema também caracteriza a Reconquista do Brasil, mas nela nota-se certa regularidade. Nos trabalhos examinados não se dá voz ao tradutor, exceto no caso de Eugênio Amado. Quem toma regularmente a palavra é o diretor da coleção, Mário Guimarães Ferri. As traduções cujos projetos descrevi parecem ter sido desenvolvidas especialmente para essa coleção, exceto o de Milton Amado e, aparentemente, a de João Etienne Filho. Mas esses trabalhos não apresentam notas do tradutor - é apenas Eugênio Amado que tem o privilégio de assinar várias notas. As publicações têm certo padrão: apresentação ou prefácio e notas do diretor da coleção, orelhas e uma excelente realização material do livro, o que não se pode dizer da primeira edição da Brasiliana.

As reedições da coleção Reconquista do Brasil, entretanto, ainda estão por serem analisadas. Seu exame é importante para a história do livro no Brasil, especialmente para se verificar como teriam servido aos propósitos definidos por Serrano (2010, p. 2) de "reinterpretar aspectos históricos brasileiros". A história do livro no Brasil está apenas esboçada - sintoma disso é que "a fonte mais rica e sistematizada de informações que dispomos 
sobre o tema" tenha sido escrita "por uma espécie de 'brazilianista'" (AMORIM, 1999, p. 15). E só temos acesso a essa obra do bibliotecário irlandês, Hallewell (2005), porque foi traduzida. Sonia Amorim (1999, p. 15) aponta que "é muito recente o interesse de nossos estudiosos da comunicação com a editoração e a memória editorial". A área tem crescido na última década, e publicações sobre a história do livro estão ganhando espaço e fornecendo maiores informações sobre esse aspecto de nossa história. No entanto, esse crescimento não tem sido acompanhado por sua contraparte, a história da tradução no Brasil. Apesar de o Brasil ter um percentual significativo de traduções entre suas publicações, pouca atenção tem sido dada à análise dos projetos editoriais e tradutórios dessas edições. Mas, como aqui apresentei, o tema é instigante.

\section{REFERÊNCIAS}

AGASSIZ, Luiz; AGASSIZ, Elizabeth Cary. Viagem ao Brasil (1865-1866). Tradução: Edgar Süssekind de Mendonça. São Paulo: Companhia Editora Nacional, 1938. (Coleção Brasiliana).

. Viagem ao Brasil: 1865-1866. Tradução: João Etienne Filho. Apresentação: Mario Guimarães Ferri. Belo Horizonte: Itatiaia, 1975. (Coleção Reconquista do Brasil).

AMORIM, Sônia Maria de. Em busca de um tempo perdido: edições de literatura traduzida pela Editora Globo (1930-1950). São Paulo: Ed. da USP: Com-Arte; Porto Alegre: Ed. da UFRGS, 1999.

BATES, Henry Walter. O naturalista no Rio Amazonas. 2 v. Tradução: Candido de Mello-Leitão. São Paulo: Companhia Editora Nacional, 1944. (Coleção Brasiliana).

. Um naturalista no Rio Amazonas. Tradução: Regina Regis Junqueira. Belo Horizonte: Itatiaia; São Paulo: EDUSP, 1979. (Coleção Reconquista do Brasil).

BURTON, Richard Francis. Explorations of the highlands of the Brazil with a full account of the gold and diamond mines. London: Tinsley Brothers, 1869. (Replica Edition by Adamant Media Corporation, 2003).

. Viagens aos planaltos do Brasil (1868). Tradução: Américo Jacobina Lacombe. São Paulo: Companhia Editora Nacional, 1941. v. 1. (Coleção Brasiliana).

. Viagens aos planaltos do Brasil. 3 v. 2. ed. Tradução: Américo Jacobina Lacombe. São Paulo: Companhia Editora Nacional, 1983. (Coleção Brasiliana).

. Viagem do Rio de Janeiro a Morro Velho. Tradução: David Jardim Junior. Apresentação e notas: Mário Guimarães Ferri. São Paulo: Itatiaia/EDUSP, 1976. (Coleção Reconquista do Brasil).

CANDIDO, Antonio. A Revolução de 1930 e a cultura. In: . Educação pela Noite e Outros Ensaios. São Paulo: Ática, 1987. p. 181-198.

DUTRA, Eliana de Freitas. Companhia Editora Nacional: tradição editorial e cultura nacional no Brasil dos anos 30. In: SEMINÁRIO BRASILEIRO SOBRE LIVRO E HISTÓRIA EDITORIAL, 1., 2004. Anais... Rio de Janeiro: Casa de Rui Barbosa, 2004. p. 1-22.

FERRI, Mário Guimarães. História da botânica no Brasil. In: ; MOTOYAMA, Shozo (Org.). História das ciências no Brasil. São Paulo: Ed. da USP, 1979-1980. v. 2, p. 33-88. 
GARDNER, George. Viagem ao interior do Brasil: principalmente nas províncias do Norte e nos distritos do ouro e do diamante durante os anos de 1836-1841. Tradução: Albertino Pinheiro. São Paulo: Companhia Editora Nacional, 1942. (Coleção Brasiliana).

. Viagem ao interior do Brasil: principalmente nas províncias do Norte e nos distritos do ouro e do diamante durante os anos de 1836-1841.. Tradução: Milton Amado. Apresentação: Mario Guimarães Ferri. São Paulo: EDUSP; Belo Horizonte: Itatiaia, 1975. (Coleção Reconquista do Brasil).

GENETTE, Gerard. Paratextos editoriais. Tradução: Álvaro Faleiros. Cotia: Ateliê Editorial, 2009.

HALLEWELL, Lawrence. O livro no Brasil: sua história. Tradução: Maria da Penha Villalobos, Lólio Lourenço de Oliveira e Geraldo Gerson de Souza. 2. ed. rev. e ampl. São Paulo: Ed. da USP, 2005.

PAGANO, Adriana. "An item called books": translations and publishers' collections in the editorial booms in Argentina and Brazil from 1930 to 1950. Crop, São Paulo, v. 6, p. 171-194, 2001.

PONTES, Heloísa. Retratos do Brasil: editores, editoras e "Coleções Brasiliana" nas décadas de 30, 40 e 50. In: MICELI, Sergio. História das Ciências Sociais no Brasil. São Paulo: Revista dos Tribunais, 1989. v. 1, p. 359-409.

RODRIGUES, Cristina Carneiro. Traduções da Coleção Brasiliana: fontes primárias. Tradução em Revista, v. 5, p. 1-17, 2008. Disponível em: <http://www.maxwell.lambda.ele.puc-rio.br/ cgi-bin/db2www/PRG_1460.D2W/INPUT0?CdLinPrg=pt. > Acesso em: 12/4/2012.

. Tradução anotada, autor-tradutor invisível: Richard Francis Burton na Brasiliana. Tradterm, v. 17, p. 67-84, 2010.

SERRANO, Gisella de Amorim. Historiografia brasileira a partir da Coleção Reconquista do Brasil. In: SEMINÁRIO NACIONAL DE HISTORIOGRAFIA, 4. Caderno de resumos \& Anais... Ouro Preto: Ed. Da UFOP, 2010. p. 1-12.

TOLEDO, Maria Rita de Almeida. A Companhia Editora Nacional e a política de editar coleções: entre a formação do leitor e o mercado de livros. In: BRAGANÇA, Aníbal; ABREU, Márcia (Org.). Impresso no Brasil: dois séculos de livro brasileiros. São Paulo: EDUNESP, 2010. p. 139-156.

WALLACE, Alfred Russel. Viagens pelo Amazonas e rio Negro. Tradução: Orlando Torres. Prefácio, notas e revisão: Basílio de Magalhães. São Paulo: Companhia Editora Nacional, 1939. (Coleção Brasiliana).

Viagens pelos rios Amazonas e Negro. Tradução: Eugênio Amado. Apresentação: Mário Guimarães Ferri. São Paulo: EDUSP; Belo Horizonte: Itatiaia, 1979. (Coleção Reconquista do Brasil).

Submetido em: 21/05/2012

Aceito em: 03/08/2012 